\title{
Black Rhinoceros in Rhodesia
}

\author{
Michael A. Kerr \& Rupert Fothergill
}

Two members of the Rhodesia National Parks Department make a preliminary reassessment of the status of the black rhinoceros Diceros bicornis in Rhodesia, and examine the techniques for estimating numbers used by Dr. H. H. Roth in his paper on White and Black Rhinoceros in Rhodesia, in ORYX, December 1967 and which, they believe, led him to overestimate the situation. They call the black rhino the hook-lipped rhino, but the more usual name has been retained in the title as being more widely understood.

\section{Methods of Estimation}

No detailed survey of the population numbers of hook-lipped rhinoceros in Rhodesia has ever been carried out. The difficulties inherent in estimating their numbers in large areas of densely wooded and often broken terrain are considerable. Between May 1967 and September 1969, while making aerial surveys of the Zambezi Valley and escarpment from Lake Kariba to the Mozambique border, mainly in order to obtain elephant and buffalo distribution patterns and population estimates, we investigated the efficacy of estimating hook-lipped rhinoceros populations from the air. In ten surveys, which covered about a quarter of the 4,000-square-mile area, the maximum number of rhinoceros counted on any one of them was only 34 . Goddard (1967), in a similar test in Tanzania, where eighty-five per cent of his study area consisted of open plains country studded with trees and shrubs, found that, even under the most favourable conditions only 50 per cent of the known population was detected, and obviously, in the densely wooded and broken country in which the great majority of rhinoceros live in Rhodesia, the value of aerial survey is even more limited. It was therefore necessary to base our estimates primarily on ground sightings, tracks and other signs, supplemented by aerial sightings in the case of the Zambezi Valley area; in addition reports from departmental staff living in areas we did not cover have been invaluable. Thus, although obtained by imprecise method, the estimates might provide a minimum figure for the overall population.

Roth and Child (1968 investigated the density and structure of the rhinoceros population marooned on the islands in Lake Kariba during the rescue operations between 1959 and 1963. The overall mean density in the studied area between the Sanyati and Mwenda rivers was one rhinoceros per $4.5-5.3$ square miles, and local abundance was found to be inversely related to the degree of human settlement. Roth (1967) considered that the population studied was relatively undisturbed and regarded these density figures 'as applicable in general to other parts of the valley'. In our opinion, however, they are high.

Mr. Kerr is Research Officer, Zambesi Valley and Mr. Fothergill is Warden, Roving Control, both in the Department of National Parks and Wild Life Management, Salisbury, Rhodesia. 
The flooding of the low-lying areas greatly reduced the areas of previously occupied habitat. Fothergill, who was in charge of rescue operations, found that rhinoceros were very poor swimmers and once out of their depth would return to land. Rhinoceros on the islands were thus unable to disperse, and, in view of the artificial conditions prevailing during the study period, the density figures would appear to be too high. Even if they are accurate it is doubtful whether they can be applied with any assurance to other areas of the mid-Zambezi valley.

The area of the valley between Kariba and the Mozambique border was widely settled by the Makorekore people up to 1958 . Although primarily agriculturists, these people hunted and snared game, using primitive weapons, and over the years they must have had a profound effect on the rhinoceros populations. We think that Roth's density figures for areas moderately to sparsely settled by the Tonga people do not necessarily apply to this area east of Kariba, and that, because of the long term settlement and associated disturbance, rhinoceros densities are considerably lower there and the distribution more patchy.

The map shows the abundance and distribution of rhinoceros in Rhodesia at the present time.

\section{Population Numbers}

Zambezi Valley - Kariba Gorge to Mozambique Border: an area of about 4,000 square miles bounded in the east by the Mozambique border and Hunyani river, in the south by the Tsetse Control game fence, and to the west and north by the Zambezi river, and Lake Kariba.

Roth considered conditions in this section of the valley to be fairly uniform, and on this basis, and using the above-mentioned density figures of $4.5-5.3$ square miles per rhino, postulated a rough estimate of $590-750$ animals. But the 'uniform conditions' assumption is erroneous. Neither the vegetation nor the terrain is homogeneous, as we know from interpretation of aerial photographs of the entire area, combined with a relatively detailed local knowledge of it. Although incomplete, Kerr's mapping of rhinoceros distribution in this area, using all ground and aerial sighting records, indicates that the animals are not uniformly distributed but are clumped in a series of pockets which, we think, are related to favourable habitat and water availability. Our information suggests that this area supports a minimum population of about 425 rhinoceros; lack of detailed knowledge makes it impossible to provide a maximum figure, but we think that Roth's figures of 590 750 animals, which he calls a very rough estimate, is over-optimistic.

This section of the Zambezi Valley is divided into seven areas: the Dande Tribal Trust Land; two game reserves and a controlled hunting area on national land; two hunting areas, and an undesignated area on unreserved land (Land Apportionment Act Chapter 257).

Dande Tribal Trust Land: The limited information available on this lightly settled area indicates a population of 40 rhinoceros.

Chewore Wilderness Area (c.1240 square miles): Roth considered that 


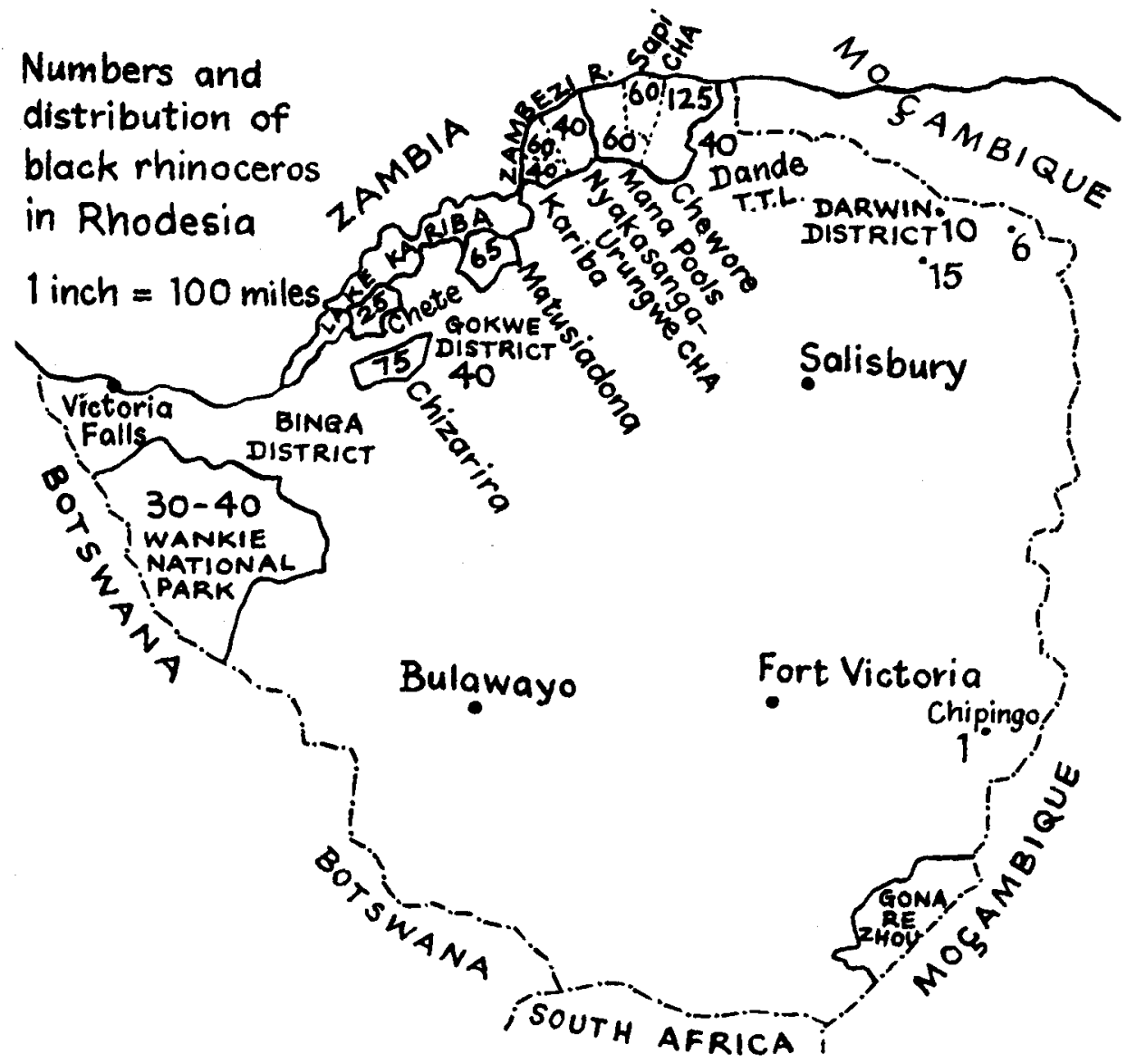

this reserve supported the densest population in Rhodesia, between 260 and 300 animals. We have no evidence for such high numbers and consider 125 a safe minimum number. This area is seldom patrolled on foot but indications are that poaching is taking a heavy toll.

Sapi Controlled Hunting Area (c. 453 square miles): A minimum figure of 60 animals is postulated. The area is predominantly dense bushland thicket and difficult to assess either from the air or on the ground.

Mana Pools Game Reserve (c. 860 square miles): Probably about 60 animals, but because of extensive sections of bushland thicket this may be too conservative.

Nyakasanga Controlled Hunting Area (c. 630 square miles): A minimum population of about 40 . As a result of heavy hunting pressure since 1960 and the lack of large areas of bushland thicket rhinoceros have probably moved into more favourable adjacent areas. They are not often seen in this area so we feel our estimate is not too conservative. Urungwe Controlled Hunting Area (c. 400 square miles): Although 
subjected to heavy hunting pressure since 1960 , the extensive areas of bushland thicket here appear to have been a refuge for the rhinoceros. Some fairly comprehensive spoor counts carried out recently by Ranger R. Hill suggest a minimum of 60 animals here.

Kariba Area (c. 407 square miles): Little information is available but a rough estimate is 400 rhinoceros.

Zambezi Valley - South of Lake Kariba For the remainder of the main distribution area Roth applied density indices varying between $4-10$ square miles per rhinoceros, and calculated a total of about 400 to 650 , of which only about 200 to 240 were possibly on national land.

Matusiadona Game Reserve (c. 539 square miles): Warden P. P. Coetsee who has had an intimate knowledge of the Reserve in recent years, estimates a population of 65 rhinoceros, but since 50 per cent of the reserve is broken mountainous terrain and difficult to cover effectively, he thinks this estimate is conservative and that the figure may be as high as 90 . The figure of 65 agrees fairly closely with the estimate of 50 - 60 animals given by Roth, who pointed out that the reserve had not been surveyed. The Tribal Trust Lands south of the reserve in the Gokwe District are known to support at least 40 rhinoceros, mostly in pockets along the Sabara, Pohwe and Sessami rivers. (Warden P. P. Coetsee and Research Officer D. Cumming).

Chizarira Game Reserve (c. 518 square miles): After a brief survey in October, 1965, Kerr estimated the population at 50 animals (Departmental Report). In an aerial survey, in September, 1968, he spotted 24 rhinoceros, and on the basis of this the population is estimated at 75 animals. In the Binga district Warden W. R. Thomson, stationed at Binga, has gathered a great deal of information on rhinoceros numbers and distribution. On tribal land, excluding the reserves, the district is considered to hold about 50 rhinoceros. For the Chete Game Reserve (353 square miles) a very rough estimate is 25 rhinoceros. Recent reports from the area indicate a high mortality rate during the past few years.

For the area south of Lake Kariba our figures suggest a minimum population of 255 rhinoceros, of which probably only 165 are on national land. These figures are well below the totals calculated by Roth which again we believe to be over optimistic.

Wankie National Park (c. 5,000 square miles): Between 1962 and 1963, 13 rhinoceros were moved to the park during the Kariba rescue operations and released there; in 1965 a further 40 animals were captured and translocated with the aid of drugs from the Mwenda Native Purchase Area (Binga district) to the park. A few of these animals have since died, and others have moved out of the park into Botswana and an adjacent controlled hunting area. For the purpose of this report the number in the park at present is estimated roughly at between 30 and 40 .

Local Occurrences. Besides' the areas discussed so far, small relic populations are known to occur in the Mount Darwin and Chipinga districts. Fothergill's survey of the Mount Darwin district indicated a population of 31 animals, in three groups of 6,10 and 15 animals, in small localities on tribal trust land. (Two of these were recently found dead.) Roth's estimate for this district was 22. A small pocket of about 
eight animals was known to occur in the Chipinga district. When Roth assessed this population there were $8-12$ animals, but a recent capture operation in the area recovered only one animal, and that only after a very intensive search.

\section{Total Population}

Roth estimated a population of between 1000 and 1400 rhinoceros with the reservation that this was only a very rough estimate. Our total is roughly 740 rhinoceros, of which about 440 occur on National Land; this is also a very rough estimate and more of a second opinion. But the welfare and future of rhinoceros outside national areas is unpredictable and highly insecure, and we feel it is safer to err on the low side for a species that is rare both in this country and elsewhere.

\section{Mortality}

Roth's comprehensive table of known rhinoceros kills in Rhodesia since 1919 gave a total of 556, which was probably, as he suggested, very conservative, and information gathered since 1967 indicates that rhinoceros poaching is still heavy in some areas. Since 1964, in the Binga district alone, 60 rhinoceros have been poached and three shot by security forces in self defence, according to Warden W. R. Thomson, and there has also been fairly heavy poaching in the Chewore Wilderness Area; in 1965 nine rhinoceros carcasses were found, and between December, 1967 and March 1968 eight were shot by insurgents from Zambia. Since 1967 the security forces in the Zambezi Valley have also shot at least eight rhinoceros in self defence. No information is available on mortality from natural causes or on the natural rate of population increase, but if rhinoceros destruction continues on this scale the population will soon be severely depleted.

\section{Conclusion}

It is evident that very little accurate information is available about the population numbers of hook-lipped rhinoceros in Rhodesia, and techniques for assessing population numbers are unlikely to improve significantly for many years. So, for some time to come, the population number will remain a rough estimate. As poaching is likely to continue to deplete their numbers it is of paramount importance that every effort is made to conserve known pockets of animals. Rhinoceros have the maximum legal protection having recently been placed on the royal game schedule, but this may be insufficient without intensive research and applied management. The conservative figure of 440 rhinoceros in protected areas gives no ground for complacency about their future, especially when our knowledge of the animal's requirements is so limited.

\section{Acknowledgments}

We would like to thank Research Officer D. Cumming and Warden P. P. Coetsee (Gokwe District and Matusiadona Game Reserve), Warden W. R. Thomson (Binga District) and Ranger R. Hill (Urungwe Controlled Hunting Area) for supplying invaluable information on rhinoceros numbers and distribution in their respective areas. 


\section{References}

CHILD, G. and SAVORY, C. R., 1964. Distribution of large mammal species in Southern Rhodesia, Amoldia I (14): 1-15.

GODDARD, J., 1967. The validity of censusing black rhinoceros populations from the air $E$, Afr. Wildl. $J$ 5: 18-23.

ROTH, H. H. and CHILD, G. 1968. Distribution and population structure of black rhinoceros (Diceros bicornis $L$.) in the Lake Kariba basin. Säugetierk. 33, 114, S. 214-226.

ROTH, H. H., 1967. White and black thinoceros in Rhodesia. Oryx 9: 217-231.

\section{Turtles in Tongaland}

In his fifth interim report on the marine turtles of Tongaland in south-east Africa, published in Lammergeyer G. R. Hughes reports a higher number of both loggerhead and leatherback females than previously recorded - 466 of the former and 77 of the latter. He repeats his proposal for a turtle reserve in Tongaland, especially in view of the fact that a recent survey of the Mozambique coast immediately to the north suggested a serious danger of both populations being exterminated there.

\section{Developers Protect Loggerheads}

The company developing Fripp Island, off South Carolina, as a resort has established a Conservation Center for the Atlantic loggerhead turtle Caretta $c$. caretta which nests there. Fripp Island Resort Inc will pay all construction costs, salaries and operating expenses for the Center, whose Hon Director is John Mehrtens, a member of FPS and Director of the Columbia Zoological Park. The Center will protect the nests, tag adults (with rewards for returned tags) and collect data.

\section{Combined Operation}

An interesting example of two introduced animals combining to destroy a habitat is described by $L$. W. McCaskill in a supplement to the New Zealand paper Forest and Bird. In the Urewera National Park there are a small number of introduced rusa deer. These are no threat to the forest themselves (though neighbouring farmers have different views), but by their movements in and out of the forest they create a system of tunnel-like tracks which make ideal habitat for opossums - and these do a great deal of damage in the forest.

\section{No Firing in the Sanctuary}

The ICBP successfully averted US Marine Corps live-ammunition training in a wildlife sanctuary on the Japanese island of Okinawa, in the Ryukyus, one of the few remaining sub-tropical virgin forest areas on the island and the breeding place of the endangered Okinawa woodpecker, believed to number not more than 100 birds. After the ICBP approach the Corps 'reappraised its original plans' and announced that there would be no firing in the area 'for an indefinite period'.

\section{Water Code in USSR}

A new code governing all water usage, including territorial water, in the USSR comes into effect in September this year. Strictly defined conditions are laid down for the discharge of all industrial and waste water into rivers or the sea, and all new plants must have anti-pollution equipment. 